\title{
Apoptosis in the germ line
}

\author{
R John Aitken, Jock K Findlay ${ }^{1}$, Karla J Hutt ${ }^{1}$ and Jeff B Kerr ${ }^{2}$
}

School of Environmental and Life Sciences, Discipline of Biological Sciences and ARC Centre of Excellence in Biotechnology and Development, University of Newcastle, Callaghan, New South Wales 2308, Australia, ${ }^{7}$ Prince Henry's Institute of Medical Research, Clayton, Victoria 3168, Australia and ${ }^{2}$ Department of Anatomy and Developmental Biology, Faculty of Medicine, Nursing and Health Sciences, School of Biomedical Sciences, Monash University, Clayton, Victoria 3800, Australia

Correspondence should be addressed to R J Aitken; Email: john.aitken@newcastle.edu.au

\begin{abstract}
Apoptosis is a critical process for regulating both the size and the quality of the male and female germ lines. In this review, we examine the importance of this process during embryonic development in establishing the pool of spermatogonial stem cells and primordial follicles that will ultimately define male and female fertility. We also consider the importance of apoptosis in controlling the number and quality of germ cells that eventually determine reproductive success. The biochemical details of the apoptotic process as it affects germ cells in the mature gonad still await resolution, as do the stimuli that persuade these cells to commit to a pathway that leads to cell death. Our ability to understand and ultimately control the reproductive potential of male and female mammals depends upon a deeper understanding of these fundamental processes.

Reproduction (2011) 141 139-150
\end{abstract}

\section{Introduction}

The term 'apoptosis' was coined by Kerr et al. (1972) to describe the process of programmed cell death in multicellular organisms. It differs from the necrotic cell death that follows acute cellular injury in being a carefully orchestrated process involving well-established biochemical entities that drive apoptosis via the 'instrinsic' or 'extrinsic' pathways (Adams \& Cory 2007). The extrinsic pathway is activated by tumor necrosis factor family receptors triggered by proapoptotic ligands such as Apo2L/TRAIL and CD95L/ FASL binding to their cognate receptors (DR4/DR5 and CD95/FAS respectively). This induces the clustering of these receptors followed by recruitment of FASassociated death domain and caspase 8 or 10, which constitute the death-inducing signaling complex. In contrast, the intrinsic apoptotic process represents a default pathway for cells that are suffering from disruption of cellular homeostasis as a consequence of stress induced by a wide variety of factors including attack by reactive oxygen species (ROS), detachment from extracellular matrix, heat, hypoxia, $\gamma$-irradiation, DNA damage, or just lack of pro-survival factors. It is regulated by the interplay of the pro- and anti-apoptotic members of the B-cell lymphoma/leukemia 2 (BCL2, Bcl-2) family of proteins (Youle \& Strasser 2008). The pro-survival members, including BCL2, BCL2L1 $\left(\mathrm{BCl}-\mathrm{x}_{\mathrm{L}}\right), \mathrm{MCL} 1$ (Mcl-1), RFC1 (A1), and BCL2L2 (BCl-w), are essential for survival in a cell type-specific manner. The multi-BH domain pro-apoptotic subfamily members, BAX, BAK1 (BAK), and possibly also BOK, are critical for activation of the downstream events that result in cell death. Finally, the pro-apoptotic $\mathrm{BH} 3$-only proteins, including $\mathrm{BCL} 2 \mathrm{~L} 11$ (BIM), BBC3 (PUMA), BID, BAD, BMF, BIK, HRK, and PMAIP1 (NOXA), initiate apoptosis signaling by activating BAX and BAK1, either through direct binding or, indirectly, through binding to pro-survival BCL2 family members, thereby unleashing BAX and BAK1 (Cragg et al. 2009, Michalak et al. 2009). Activation of BAX/BAK1 proteins is followed by release of cytochrome $c$ and other apoptogenic factors from the mitochondria, resulting in the formation of the apoptosome, which promotes activation of caspase 9 with subsequent activation of the effector caspases (e.g. caspases 3 and 7).

Functionally, apoptosis is thought to play a major role in tissue morphogenesis during development, in the physiological regulation of cell number, and in mediating the cellular response to adversity. Within the germ line, apoptosis may serve all of these functions depending on the stage of development, the nature of the extracellular environment, the status of intracellular metabolism, the integrity of the cell, and whether it is the male or female germ line under consideration. 


\section{Apoptosis in the male germ line}

\section{Spermatogenesis}

The testis produces spermatozoa from spermatogonia in a complex developmental cascade involving proliferation, meiotic maturation, and subsequent differentiation of germ cells in the germinal epithelium lining the seminiferous tubules. This process is called spermatogenesis and its duration varies considerably between species ranging from 35 days in mice to 50 days in rats and 70 days in humans. Although daily sperm production from paired testes is impressive $(\sim 1000$ new spermatozoa produced every second in man) up to $75 \%$ of the theoretical sperm yield may be lost during spermatogenesis, depending on the species. Degeneration and death among male germ cells can occur in any phase of spermatogenesis and is attributable to intrinsic or acquired disturbances of cell viability resulting in apoptosis.

\section{Apoptosis in the testes}

Apoptosis in male germ cells occurs also during fetal life in pro-spermatogonia/gonocytes when the testes are differentiating and adjustments have to be made to achieve the optimal ratio of germ cells to Sertoli cells. During this developmental process, excess premeiotic spermatogonia are removed by an early wave of apoptosis that accompanies the first round of spermatogenesis in the testes. Impairment of apoptosis through the functional deletion of key mediators of this process generates a male infertility phenotype due to an imbalance in germ cell and Sertoli cell numbers (Rodriguez et al. 1997). Later in life, apoptosis is involved in the removal of germ cells that are damaged as a result of exposure to environmental toxicants, chemotherapeutic agents, or heat (Wang et al. 2007). A role of apoptosis in the etiology of spontaneous male infertility has also been suggested by virtue of the excessively high numbers of apoptotic germ cells observed in the testes of some infertile males (Lin et al. 1997). In addition, apoptotic markers including caspase activation and phophotidylserine exteriorization have been discovered in the mature spermatozoa of male infertility patients (Barroso et al. 2000, Paasch et al. 2004, Almeida et al. 2009, Grunewald et al. 2009, Aitken \& Curry 2011). Since apoptosis in mature spermatozoa appears to be critically involved in the induction of a subfertile state, it is this aspect of the apoptotic process that we shall focus on in the first part of this review.

\section{Apoptosis in spermatozoa}

Interest in the ability of mature spermatozoa to undergo apoptosis has surfaced recently with the discovery that human spermatozoa frequently exhibit high levels of
DNA fragmentation, an archetypal signature of this process (Aitken \& De luliis 2007, 2010). This DNA damage is a significant factor in defining the functionality of spermatozoa and has been linked with a wide variety of adverse clinical outcomes including impaired fertilization, disrupted preimplantation embryonic development, poor implantation rates, and an increased incidence of miscarriage (Aitken \& De luliis 2007, Zini et al. 2008, Aitken et al. 2009). DNA damage in the male germ line is also thought to have an impact on the health and well-being of children and presumably underpins the relationships that have been repeatedly observed between paternal age, which is positively correlated with sperm DNA damage (Singh et al. 2003) and morbidity in the offspring including: i) dominant genetic diseases such as achondroplasia; ii) complex neurological conditions including spontaneous schizophrenia, epilepsy, bipolar disease, and autism; and iii) an increased rate of death in the F1 generation associated with congenital malformations, injury, and poisoning (Sipos et al. 2004, Reichenberg et al. 2006, Frans et al. 2008, Zhu et al. 2008, Green et al. 2010).

Some of this morbidity is certainly due to an agedependent increase in the mutational frequency carried by the germ line as a result of replication errors in the spermatogonial stem cell population. These mutations appear to persist in the germ line because they confer upon the mutant germ cells a selective advantage that leads to their preferential clonal expansion within the testes; for example, this appears to be the case for Apert's syndrome and some germ cell tumors (Goriely et al. 2009). However, another potential mechanism for malemediated mutagenic change involves the aberrant repair of sperm DNA damage in the oocyte following fertilization (Fig. 1). Thus, once fertilization has occurred, the oocyte will suppress DNA synthesis in both the male and female pronuclei as it engages in a round of DNA repair (Shimura et al. 2002). If the oocyte makes a mistake at this point, a mutation may be created, which, because it precedes the $\mathrm{S}$ phase of the first mitotic division, will be in every cell in the body. As a consequence of such aberrant repair, apoptosismediated DNA damage in spermatozoa could translate into an increased mutational load carried by the offspring. These mutations might directly impair the viability or health of the F1 generation as in the case of achondroplasia (Hurst \& Ellegren 2002, Aitken et al. 2004, Aitken \& De luliis 2007) or, if the organization of the DNA is sufficiently disrupted, impair meiosis in F2, further exacerbating the damage to the germ line (Joffe 2010). Through such mechanisms, an environmentally induced, apoptosis-mediated insult on DNA integrity in the male germ line could have trans-generational impacts on the health and fertility of future generations of descendants (Fig. 1). Furthermore, modern-assisted conception techniques such as ICSI only enhance the risk of genetic damage being either created in or 


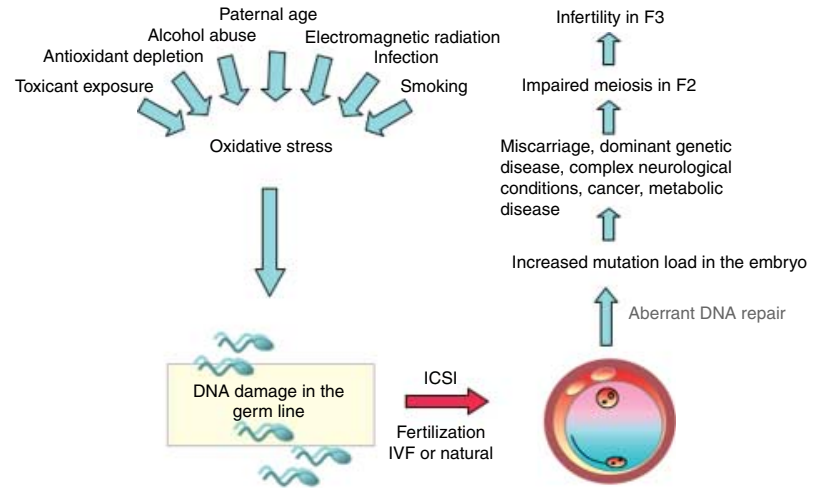

Figure 1 Hypothesis suggesting one of the mechanisms by which DNA damage in human spermatozoa can increase the mutational load subsequently carried by the embryo. This scheme proposes that a variety of environmental factors can conspire to induce a state of oxidative stress in the male germ line. The DNA-damaged spermatozoa then fertilize the egg and the latter rapidly engages in a round of DNA repair. If this DNA repair is incomplete or inaccurate then mutations may be generated that will influence the survival and well-being of the $\mathrm{F} 1$ generation. It has also been suggested that if, as a result of this process, the DNA possesses profound structural defects, this may ultimately influence the normality of meiosis, and hence, fertility in future generations.

transferred to the progeny by facilitating fertilization with DNA-damaged spermatozoa in vitro that would have been rejected in vivo.

\section{Biological significance of apoptosis in spermatozoa}

Given the biological importance of DNA damage in the male germ line, it is essential that we now determine the cause of this pathology. In this context, three major hypotheses have been advanced: i) DNA fragmentation in spermatozoa may be the result of unresolved strand breaks created during the normal process of spermiogenesis in order to relieve the torsional stresses involved in packaging DNA into the sperm head. Normally, these 'physiological' strand breaks are corrected by a complex process involving $\mathrm{H} 2 \mathrm{Ax}$ phosphorylation and the subsequent activation of nuclear poly(ADP-ribose) polymerase and topoisomerase (Meyer-Ficca et al. 2009). However, if spermiogenesis should be disrupted for some reason then the restoration of these cleavage sites might be impaired and the spermatozoa, lacking any capacity for DNA repair in their own right, would be released from the germinal epithelium still carrying their unresolved strand breaks. ii) These strand breaks could also represent the induction of an incomplete, abortive apoptotic response during spermatogenesis that achieved endonuclease-mediated DNA cleavage but failed to compromise cell viability. iii) Alternatively, the strand breaks may be the end result of oxidative stress. A recent analysis of DNA damage in the male germ line has demonstrated an extremely close relationship between DNA fragmentation (TUNEL) and oxidative
DNA base damage in spermatozoa, as reflected by the presence of 8 -hydroxy, $2^{\prime}$ deoxyguanosine $(8 \mathrm{OHdG})$, a major metabolic product of DNA oxidation (De luliis et al. 2009b; Fig. 2). Furthermore, cause and effect have been confirmed by demonstrating that the direct exposure of normal spermatozoa to ROS $\left(\mathrm{H}_{2} \mathrm{O}_{2}\right)$, or levels of electromagnetic radiation that will trigger endogenous ROS generation, results in a subsequent increase in oxidative DNA damage and DNA fragmentation (Aitken et al. 1998, De luliis et al. 2009a). Since the oxidative stress seen in defective human spermatozoa appears to involve mitochondrial superoxide generation, and mitochondrial ROS is a typical feature of apoptosis (Koppers et al. 2008, De luliis et al. 2009a), a significant involvement of apoptosis in the etiology of DNA damage in the male germ line seems likely.

\section{DNA damage is correlated with impaired spermiogenesis}

Another important factor to be considered in relation to the induction of DNA damage in the male germ line is the role played by impaired spermiogenesis (the differentiation of haploid round spermatids into spermatozoa).
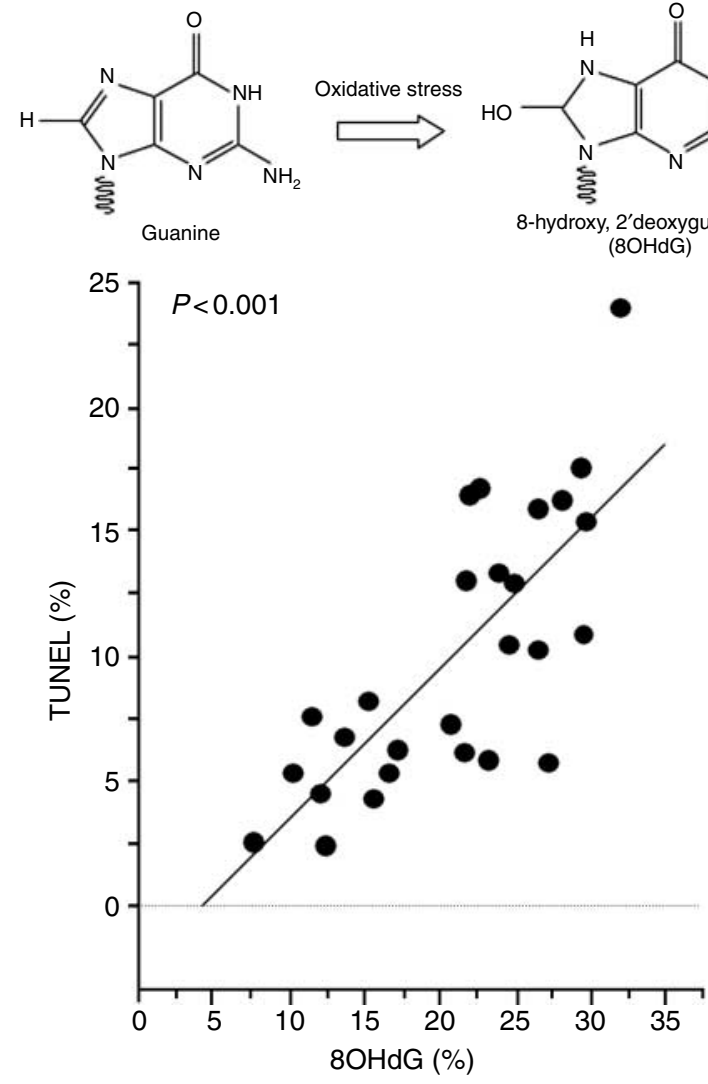

Figure 2 Powerful correlation observed between DNA fragmentation in human spermatozoa and oxidative DNA base damage as indicated by the presence of 8-hydroxy, 2' deoxyguanosine (8OHdG). Modified from De luliis et al. (2009a, 2009b). 
Thus, several authors have found that DNA damage in spermatozoa is highly correlated with the efficacy of sperm chromatin protamination, measured using the probe chromomycin (CMA3; Bianchi et al. 1993, De luliis et al. 2009b). This link between defective spermiogenesis and DNA damage is further supported by the fact that several independent studies have also recorded correlations between DNA damage in human spermatozoa and elements of the conventional semen profile (specifically sperm count and morphology), which, in turn, reflect the efficiency of the spermatogenic process (Lolis et al. 1996, Iranpour et al. 2000, Irvine et al. 2000). Spermiogenesis is itself highly susceptible to oxidative stress because isolated spermatids have a limited capacity for both DNA repair and glutathione replenishment (Den Boer et al. 1990). Throughout this phase of development these haploid germ cells are highly dependent on the nurturing activity of Sertoli cells, which possess high levels of antioxidant enzymes including superoxide dismutase and the transferase, peroxidase, and reductase activities of the glutathione cycle (Bauché et al. 1994). It may also be significant that spermiogenesis is entirely dependent on the regulated translation of preexisting mRNA species. Experimental studies in Escherichia coli indicated that severe oxidative stress can induce protein mistranslation through impairment of an aminoacyl-tRNA synthetase editing site (Ling \& Söll 2010). If protein translation should be disrupted in this way when differentiating spermatids are placed under oxidative stress, it would explain the close relationship between such stress and disrupted spermiogenesis. Indirect evidence for this relationship is seen in the experimental induction of oxidative stress in the testes with the organophosphorous pesticide, methyl-parathion (Piña-Guzmán et al. 2006). Administration of this compound was found to generate oxidative stress that then impaired spermiogenesis, resulting in high levels of DNA damage in the spermatozoa.

\section{Defective spermiogenesis and apoptosis}

It is not just the process of spermiogenesis that appears to be vulnerable to oxidative stress; the defective spermatozoa produced as a consequence of this process also appear to be sensitive to this form of attack for two reasons. First, if chromatin remodeling has been disrupted, then the spermatozoa's DNA will be relatively nucleohistone rich. The persistence of histones impairs normal chromatin compaction (by excluding protamines), leaving the DNA relatively open and vulnerable to oxidative damage (Bennetts \& Aitken 2005). This conclusion is supported by the extremely close correlations that have been recorded between CMA3-based assessments of chromatin remodeling during spermiogenesis, DNA fragmentation, and oxidative DNA damage (Fig. 3; De luliis et al. 2009b, Aitken \& De luliis 2010). Secondly, defective spermatozoa generated in an

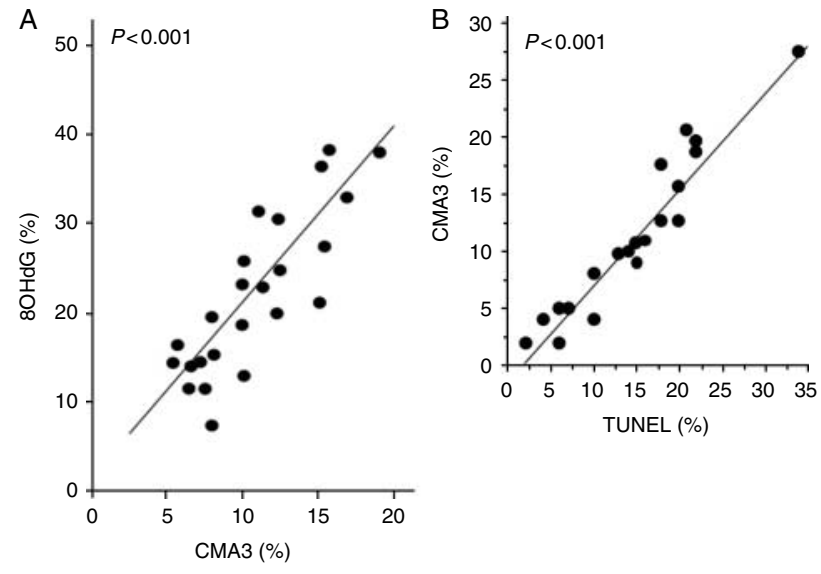

Figure 3 Close relationship between the efficiency of chromatin remodeling as monitored by CMA3 fluorescence and DNA damage in spermatozoa. (A) Correlation between CMA3 and $8 \mathrm{OHdG}$.

(B) Correlation between CMA3 and DNA fragmentation as measured by the TUNEL assay. Modified from De luliis et al. (2009a, 2009b).

environment of oxidative stress and impaired spermiogenesis have a tendency to default to an apoptotic pathway associated with cell senescence. Mature spermatozoa have the potential to exhibit many of the features of apoptosis including activation of caspases 1 , 3,8 , and 9 , annexin- $\mathrm{V}$ binding, mitochondrial generation of ROS, and DNA fragmentation (Barroso et al. 2000, Paasch et al. 2004, Koppers et al. 2008, Aitken \& De luliis 2010). Although many of the reagents that have been shown to induce apoptosis in somatic cells (staurosporine, lipopolysaccharide, 3-deoxy-D-manno-octulosonic acid (Kdo), and genistein) are ineffective with human spermatozoa, these cells will default to the intrinsic apoptotic pathway in response to oxidative stress. Thus, exposure of human spermatozoa to $\mathrm{H}_{2} \mathrm{O}_{2}$ can readily trigger an apoptotic cascade characterized by the activation of caspase 3 and the appearance of annexin- $V$ binding positivity (Lozano et al. 2009). Furthermore, preexposure of human spermatozoa to antioxidants, such as melatonin or catalase, will prevent this apoptotic response to oxidative stress (Espino et al. 2010, Libman et al. 2010). Such an apoptotic cascade can also be precipitated by a variety of factors that induce oxidative stress in spermatozoa by triggering free radical generation by the mitochondria, including exposure to radio-frequency electromagnetic radiation (De Iuliis et al. 2009a), unsaturated fatty acids (Aitken et al. 2006, Koppers et al. 2010), and exposure to the phosphoinositide 3 kinase (PI3 kinase) inhibitor, wortmannin (A Koppers \& RJ Aitken, unpublished observations).

\section{Function of apoptosis in spermatozoa}

We propose two major roles of apoptosis in mature spermatozoa. First, this is a mechanism for functionally deleting damaged germ cells. In somatic tissues, the end 
point of apoptosis is the activation of caspases that then stimulate a cytoplasmic endonuclease, caspaseactivated DNase (CAD) that, in combination with other nucleases released from the mitochondria (endonuclease $G$ and apoptosis-inducing factor), move to the nucleus to induce DNA cleavage and complete the execution process. However, in spermatozoa this process is prevented by the physical architecture of the cell (the mitochondria and nucleus are in different cellular compartments) and the condensed nature of the chromatin. Apoptosis induces motility loss, which deletes the spermatozoa in an immediate functional sense, however, this process is inefficient and may not completely eliminate the cells' competence for fertilization (Aitken et al. 1998, De luliis et al. 2009a, Koppers et al. 2010). As a result, it is perfectly possible for apoptotic spermatozoa, possessing high levels of DNA fragmentation, to fertilize the oocyte (Aitken et al. 1998), particularly when ICSI is involved (Twigg et al. 1998). Further evidence that DNA damage in spermatozoa is not the efficient executioner and that it is in somatic cells is seen in the correlations that have been repeatedly observed between DNA damage in the germ line and miscarriage or morbidity in the offspring. In such cases, conception must have occurred irrespective of the DNA damage in the sperm nucleus (Aitken et al. 2009). This is the price the spermatozoon pays for its highly compactible chromatin, for while the latter might protect the DNA to some extent (Bennetts \& Aitken 2005), it also impedes the ability of apoptosis to rapidly eliminate these cells. The only element of the apoptotic cascade which can induce DNA damage is the ROS released from the mitochondria and it is for this reason that most of the DNA damage seen in human spermatozoa is oxidative in nature (De luliis et al. 2009b). More extensive DNA fragmentation may occur postmortem as a result of the activation of endonucleases that are integrated into the sperm chromatin, thus finalizing the destruction of the cell (Sotolongo et al. 2005).

The second function of apoptosis in spermatozoa is that it represents a form of regulated senescence that permits the fast, efficient, silent removal of these cells from the male and female reproductive tracts once viability has been lost. The reason for this is that the presence of specific apoptotic markers, such as phosphatidylserine, on the surface of apoptotic cells informs incoming phagocytes that removal of the target cells should be silent, in the sense that there should be no oxidative burst or production of pro-inflammatory cytokines (Kurosaka et al. 2003). This occurs, for example, when senescent neutrophils are being removed by macrophages from the sites of tissue repair (Leitch et al. 2008). Since it is the fate of a majority of spermatozoa to die in the female reproductive tract following insemination, it is essential that the effective removal of these dead and moribund cells is achieved in the absence of inflammation (Rossi \& Aitken 1997).
The presence of apoptotic markers on the sperm surface permits such a silent phagocytic removal to occur.

While spermatozoa are supposed to undergo apoptosis in the female reproductive tract following insemination, it is possible that the high levels of apoptosis and DNA damage seen in the spermatozoa of subfertile males represent the premature activation of this regulated senescence pathway (Almeida et al. 2009, Aitken \& De luliis 2010). Such reasoning may explain why the ejaculates of male infertility patients are frequently associated with enhanced levels of leukocytic infiltration (Aitken et al. 1994, Tremellen \& Tunc 2010).

\section{Apoptosis and pro-survival factors}

If apoptosis represents a default pathway of regulated senescence for mammalian spermatozoa, what normally prevents these cells from entering this pathway? The key to this process is the phosphorylation status of two key defenders of cellular integrity - PI3 kinase and its target AKT (protein kinase B). When these molecules are not adequately phosphorylated, a key substrate molecule, BCL2-associated death promoter (BAD), also becomes dephosphorylated. This leads to BAD breaking away from its binding protein, 14-3-3 and in this unfettered state, moving rapidly to the mitochondria. When BAD reaches the mitochondria, it participates in a process of pore formation that leads to the leakage of mitochondrial factors into the cytoplasm such as Endo G, AIF, and, most important of all, cytochrome $c$. Spermatozoa possess their own form of cytochrome $c$ and it is three to five times more powerful an inducer of apoptosis than the somatic version of this protein (Liu et al. 2006). It is also a particularly powerful scavenger of ROS and may help limit the release of these powerful mediators of inflammation to the outside of the cell (Liu et al. 2006).

If the PI3 kinase pathway is essential for the maintenance of cell viability then we might ask what pro-survival factors normally stimulate this pathway in order to keep spermatozoa from defaulting to this program of regulated senescence and apoptosis. Such factors must exist. Traditionally, when we are performing IVF, spermatozoa are suspended in simple balanced salt solutions, the critical components of which are thought to be calcium, bicarbonate, and a protein source such as albumin to help remove cholesterol from the plasma membrane. In such media, capacitation will occur in a matter of $2-5 \mathrm{~h}$, but the cells have lost their motility in 12-24 h (Alvarez et al. 1987). However, in vivo sperm survival is an order of magnitude longer since these cells must be able to survive for up to a week in the epididymis as they complete their maturation and up to another week in the female tract as they wait for an egg to arrive. Clearly, in vivo pro-survival factors are operating that are missing from our in vitro culture media.

In order to understand the nature of these pro-survival factors we need to understand what receptors are on the 
surface of these cells that might be able to maintain high levels of PI3 kinase activity and thereby prevent apoptosis. To achieve this aim, we have undertaken a detailed proteomic analysis of human spermatozoa, which has revealed a number of potential receptors that might fulfill this role (Baker et al. 2007). One of the receptors identified in this screen was for prolactin. We have subsequently demonstrated that the human spermatozoon has four different isoforms of the prolactin receptor on its surface, the long and three variants of the short form, one of which is unique to the male gamete. Critically, prolactin stimulates PI3 kinase activity, maintains AKT phosphorylation, and has a powerful pro-survival effect on human spermatozoa (Pujianto et al. 2010). There is no reason to believe that prolactin is the only or even the most powerful pro-survival factor of human spermatozoa; however, it is the first such factor to be identified. Its discovery heralds a new era in our understanding of sperm cell biology by emphasizing the dependence of these cells on survival factors that, through activation of PI3 kinase-AKT phosphorylation, prevent spermatozoa from entering an apoptotic pathway that culminates in cell death.

\section{Apoptosis in the female germ line Cell dynamics in the ovary}

From its earliest differentiation until the time when it is no longer capable of ovulation, the ovary exhibits constant remodeling, whereby new cells and tissues are formed and others degenerate. The population of female germ cells is itself a reflection of the balance between their survival and death in prenatal and postnatal life. Controlled self-destruction of germ cells (apoptosis) is thought to predominate in fetal life, in contrast with the postnatal ovary where elimination of oocytes in growing follicles is a characteristic feature of atresia. However, whether this process is driven primarily by the oocyte or is a secondary response to the degeneration of granulosa cells is uncertain at the present time and requires further research. The development and growth of germ cells and follicles in mammals has been thoroughly reviewed by Byskov \& Nielsen (2003).

It is estimated that more than $99 \%$ of the germ cells generated during ovarian development are lost through mechanisms involving apoptosis, with most never reaching ovulation. Germ cells are lost in the greatest numbers immediately prior to and during the process of primordial follicle formation, which occurs during embryonic and early postnatal development. Accumulating evidence from knockout mouse studies, expression analyses, and in vitro models of oogenesis supports a role of the BCL2-regulated apoptotic pathway in the developmentally regulated death of primordial germ cells, oogonia, and oocytes during the embryonic period. Further research is needed to identify which members of the BCL2 family are involved and when during the embryonic period. Alternative mechanisms, such as autophagy, are also emerging as key regulators of primordial oocyte death during the early postnatal period. While atresia is thought to originate in the oocyte in primordial follicles, once these follicles enter the growth pathway to become primary to antral follicles, apoptosis begins in the somatic granulosa cells, eventually leading to death of the oocyte and elimination of the follicle. Follicular atresia will not be addressed in this review.

\section{Establishment of the ovarian pool of primordial follicles}

Much of our knowledge on the formation of primordial follicles comes from studies in mice. Oogenesis begins at E7.5 with the allocation of the embryonic precursors of adult gametes (oocytes), known as primordial germ cells. Approximately 45 cells make up the founder population and these migrate from their origin at the base of the allantois through the hindgut to colonize the genital ridge by E11.5 (McLaren 2000). Once in the gonadal anlage, the primordial germ cells migrate centrally forming primitive sex cords after which they cease motility and are called oogonia. However, these cells proliferate extensively during their migration and continue to do so as oogonia after colonization of the gonads (De Felici et al. 2005). The oogonia then begin forming nests, beginning at E10.5 in mice, and are connected by intercellular bridges. Proliferation ceases for some oogonia by E13.5, with the number of germ cells peaking at $\sim 26000$ (Borum 1961, Tam \& Snow 1981). The oogonia subsequently enter the first stages of meiosis and differentiate into primary oocytes (Fig. 4) at which point proliferation is no longer possible (McLaren 1988). At this time their intercellular bridges are

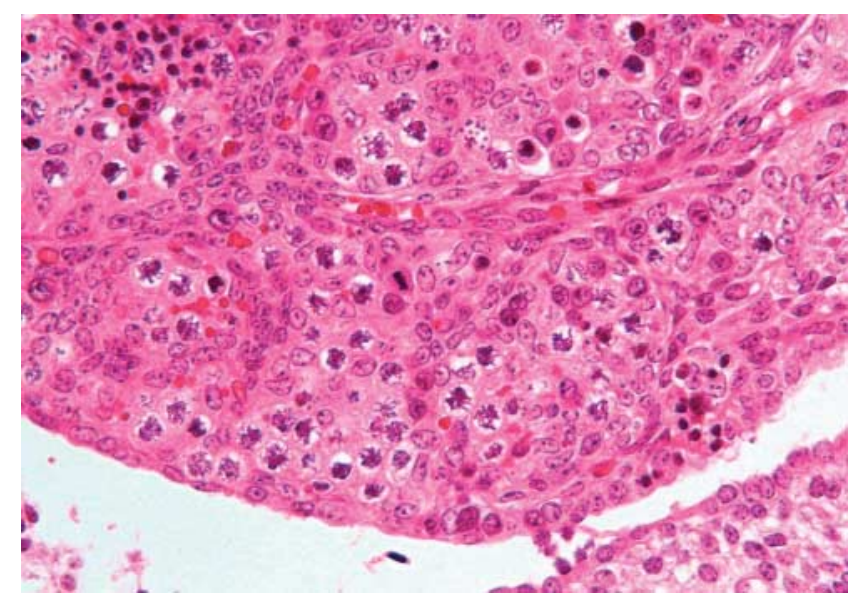

Figure 4 Mouse ovary embryonic day 17 . The germ cells (oocytes) are in prophase I of meiosis and show thickened chromosomes, characteristic of pachytene. Oocytes are clustered in nests in which somatic or pregranulosa cells do not enclose individual germ cells. Most of the small, scattered pyknotic elements are apoptotic oocytes. 
dissolved and individual oocytes become enclosed in a layer of pregranulosa cells. Around the time of birth, the enclosed oocytes arrest in meiotic prophase I at diplotene and become primordial follicles (Fig. 5) with the entire process of follicle formation being complete by postnatal day PN7 (Kerr et al. 2006, Pepling 2006). The process of human primordial follicle endowment is analogous, with the peak in germ cell number at midgestation, and the completion of primordial follicle assembly before birth (Motta et al. 1997).

The number of primordial follicles established within the ovary during development is the combined result of both extensive proliferation and death of primordial germ cells, oogonia, and oocytes. It is important to note that once formed in primordial follicles, oocytes cannot undergo proliferation by cell division. Thus, the continuous death of germ cells throughout embryonic development and into early neonatal life results in the loss of two-thirds or more of germ cells generated, such that in C57/BL6 mice fewer than 10000 germ cells remain to make up the ovarian reserve at birth and only 2000 primordial follicles remain at PN7 (Kerr et al. 2006). Death occurs at all stages of oogenesis, but a wave of attrition involving a large proportion of the germ cells present has been documented in the mouse at E13.5-E15.5, when oogonia cease mitosis and enter into meiosis. A second wave of loss occurs during the breakdown of oogonial nests between E17.5 and PN1 in mice, which is coincident with the assembly of oocytes into primordial follicles (Coucouvanis et al. 1993, Ratts et al. 1995). The strains of mice used by these authors (C57BL and ICR wild-type (WT) female mice respectively) may be significant since variation in oogonial loss is thought to be heavily dependent on genotype. The germ cells lost during these waves before the formation of oocytes in primordial follicles exhibit

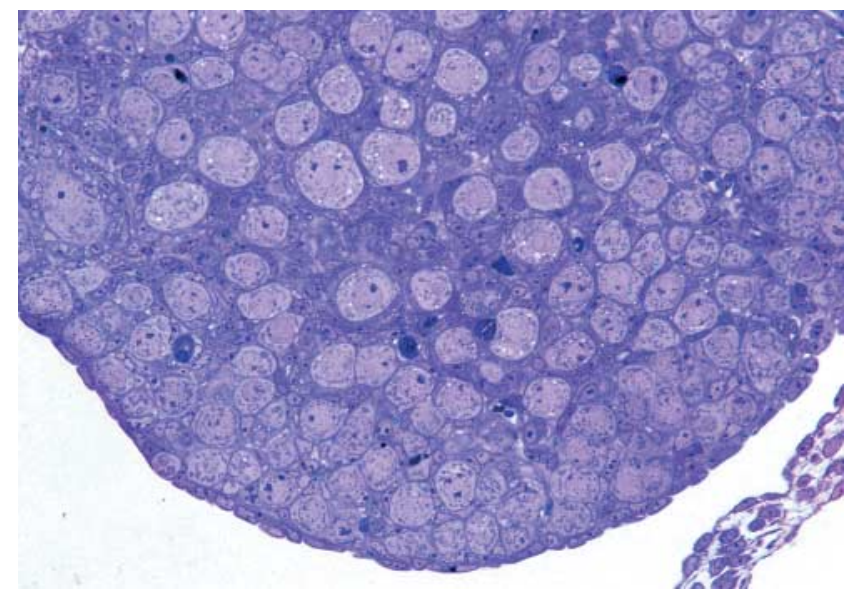

Figure 5 Mouse ovary postnatal day 1. All of the oocytes are arrested at diplotene of meiosis I and most are enclosed by granulosa cells, forming primordial follicles. With the exception of erythrocytes in capillaries, all other densely staining elements are oocytes at various stages of degeneration. nuclear condensation, cell shrinkage and fragmentation, and DNA laddering with positive TUNEL staining, and PARP1 immunoreactivity, all of which are characteristics typically associated with apoptosis (Coucouvanis et al. 1993, Pesce \& De Felici 1994, Pepling \& Spradling 2001, Ghafari et al. 2007, Lobascio et al. 2007a, 2007b).

\section{Developmentally programmed cell death during ovar- ian development: BCL2-mediated apoptosis}

There is mounting evidence to suggest that the death of primordial germ cells, oogonia, and oocytes, which occurs during the ovarian development in both mice and humans, is mediated through the actions of the BCL2 family of proteins (Ratts et al. 1995, Rucker et al. 2000, Flaws et al. 2001, Jefferson et al. 2006, Greenfeld et al. 2007, Lobascio et al. 2007 b, Albamonte et al. 2008, De Felici et al. 2008).

Gene overexpression and knockout studies in mice have demonstrated that deregulation of the BCL2regulated apoptosis pathway has a dramatic effect on the initial number of primordial follicles making up the ovarian reserve. Deletion of the pro-apoptotic protein BAX yields increased oocyte numbers as primordial follicles in neonatal ovaries when compared with WT (Greenfeld et al. 2007). The role of BAX in primordial germ cell, oogonial, and oocyte death is also supported by the observation that BAX expression is upregulated in ovaries during follicular endowment and in cultured fetal oocytes undergoing apoptosis (De Felici et al. 1999). BAX expression in oocytes of the human fetal ovary has been detected from the 14th week until term (Vaskivuo et al. 2001). If the antiapoptotic protein BCL2L1 is deleted, the neonatal ovaries have a deficiency of oocytes apparently due to a failure to survive during embryonic life (Rucker et al. 2000). Deletion (Ratts et al. 1995) or overexpression (Flaws et al. 2001, 2006) of BCL2 leads to either reduced oocyte endowment or enhanced oocyte endowment respectively. Collectively, these studies provide clear evidence of the role of the BCL2-regulated apoptotic pathway in establishing the pool of primordial follicles. However, there remain a large number of other members of the BCL2 (and BH3-only proteins) family, which have not been examined with respect to regulating the primordial pool.

\section{Apoptosis in the early postnatal ovary}

Contrary to germ cell death during prenatal ovarian development, the contribution of classical apoptotic pathways to the developmentally driven death of oocytes in the postnatal ovary is less clear. Apoptosis appears to be one of many mechanisms for eliminating oocytes from the germ line once the initial pool of primordial follicles has been established. Tingen et al. (2009) 
evaluated the expression of four morphological or biochemical markers typically associated with apoptosis: nuclear condensation/cell shrinkage, active caspase 3, cleavage of poly(ADP-ribose) polymerase 1 (PARP1), and DNA fragmentation within the primordial follicle population of prepubertal and young adult mice (PN6-26). These hallmarks were not commonly observed in primordial follicles in any of the ovaries examined, despite the fact that empirically derived follicle numbers and mathematical models of follicular dynamics indicate the loss of 155 primordial follicles per day per ovary during this stage of development. These observations were supported by Rodrigues et al. (2009), who also failed to detect significant numbers of PARP1, caspase 3, and TUNEL-positive oocytes in the postnatal ovary (Rodrigues et al. 2009). However, these authors did provide evidence to suggest autophagy as an alternative mechanism for oocytes loss in the postnatal ovary, at least during the perinatal period.

\section{Biological significance of apoptosis during primordial follicle endowment}

The reason behind the massive depletion of germ cells during prenatal and neonatal ovarian development remains unknown, though several hypotheses have been suggested. The first is death by defect, where germ cell loss may relate to poor quality due to reduced DNA integrity. This loss of DNA integrity in the fetal oogonia may be related to high levels of oxidative DNA damage in these cells, which may, in turn, depend on such factors as maternal nutritional status during pregnancy (Murdoch et al. 2003). Mice bearing mutations in genes essential for chromosome pairing, homologous recombination, DNA repair, and synapse formation during the early stages of the first meiotic prophase (which occurs immediately prior to meiotic arrest and primordial follicle assembly) invariably have ovaries devoid of oocytes and are infertile (Barlow et al. 1996, 1998, Pittman et al. 1998, Yoshida et al. 1998). These studies indirectly suggest that low-quality oocytes, arising as a result of errors made during meiotic recombination or following exposure to high levels of oxidative stress, are eliminated from the ovary. Alternatively, failure of germ cells to accumulate adequate energy supplies and cytoplasmic organelles may mark them for elimination, while a surfeit of organelles and energy stores may promote survival (Pepling \& Spradling 2001). A second hypothesis involves death by selfsacrifice. Pepling \& Spradling (2001) believe that this is necessary to break the intercellular bridges between oogonia, allowing the somatic cells to permeate the nests and form primordial follicles. A third possibility is that some cells undergoing death may serve as nurse cells, supplying neighboring oogonia with additional nutrients and organelles via their connecting intercellular bridges (Pepling \& Spradling 2001). The depleted nurse cells are subsequently eliminated during nest breakdown. A final hypothesis is death by neglect, whereby apoptosis may be triggered in germ cells that do not receive adequate cell-extrinsic growth factor or somatic cell support (Tilly 2001). It is possible that several of these processes could be responsible for the depletion of germ cells, oogonia and oocytes.

The collective evidence from the aforementioned studies suggests that primordial germ cell-, oogonial-, and oocyte-death may be required for the endowment of primordial follicles of sufficient quality to support female fertility and to ensure development of healthy offspring (Guigon \& Magre 2006). However, this wave of death must be tightly controlled to ensure that there are sufficient oocytes to support a fertile life span of adequate length. Numerous studies demonstrate that a reduction in the supply of primordial follicles results in premature ovarian failure, which has significant negative consequences for female fertility and health, including early risk of osteoporosis and heart disease (Shuster et al. 2010). Conversely, it is not yet clear how interventions that increase follicle numbers might impact fertility, both in terms of fertile life span and oocyte quality, as well as the health of the offspring. BCL2 overexpression mice have significantly more primordial follicles at PN4 than WT mice, but by PN60 the number of follicles was no different to WT (Flaws et al. 2001), suggesting that germ cells that fail to die during development are slated for death during postnatal development. By contrast, inactivation of the pro-apoptotic $B A X$ gene elevated follicle numbers and significantly prolonged fertility into advanced age. In a unique study, Perez et al. (2007) showed that loss of BAX prolonged the life span of the ovary into advanced age but did not lead to a higher incidence of ovarian tumors. Equally important, many age-related problems such as bone and muscle loss were minimized. However, it is not clear from these studies if the rescue of follicles fated for death by depletion of BAX compromised oocyte quality and threatened offspring health. Thus, it is likely that the retention of adequate follicle numbers must be balanced with the critical need to eliminate damaged or defective oocytes to ensure optimal oocyte quality and healthy offspring development. How this balance is maintained is yet to be clearly elucidated.

\section{Apoptosis in the male and female germ lines}

It is clear from this review that apoptosis is a critical process in regulating the availability of healthy germ cells that will differentiate into gametes and ultimately participate in fertilization. In both the male and the female gonad, apoptosis is clearly important during embryonic development in regulating the size of the spermatogonial stem cell and primordial follicle - pools that will ultimately define an individual's reproductive potential. Thus, it is through apoptosis in the germ line 
that the optimal ratio of germ cells to nurse cells (Sertoli cells and prefollicular cells) is established to ensure the establishment of a functional gonad. It is also through this apoptotic process that the quality of the germ cells entering the reproductive pool is ensured. Quality control of the germ line is also a major function of apoptosis following puberty. In males, spermatozoa are produced throughout adult life although the quality of these cells may be extremely variable, especially in man (Aitken et al. 2009). As soon as spermatozoa become oxidatively stressed they appear to default to an apoptotic pathway designed to ensure that inferior quality gametes will not participate in the process of fertilization. Similarly, in the ovary there is a massive loss of primordial follicles with the apparent purpose of ensuring the quality of oocytes advancing to ovulation and conception.

In males, the mechanisms responsible for depletion of defective spermatozoa bear many of the hallmarks of the intrinsic apoptotic cascade (mitochondrial ROS generation, caspase activation, and phosphatidylserine exposure) but the final step in this process, endonuclease-mediated DNA cleavage, cannot occur because the nucleus and mitochondria are in different compartments of the cell and the chromatin is too densely packed to permit endonuclease entry. The extensive fragmentation of sperm DNA seen in infertile patients may be a postmortem change induced by the entry of extracellular nucleases into the spermatozoa following cell death and a loss of membrane integrity. Such a proposal would be in keeping with the presence of powerful nucleases in the fluids of the lower male reproductive tract and the fact that most TUNEL-positive human spermatozoa are no longer viable (Boaz et al. 2008, Aitken et al. 2010). By contrast, in the female germ line there is no compartmentalization of the nucleus and mitochondria as we see in spermatozoa. As a result, there would appear to be no physical reason why the oocyte would not be competent to undergo apoptosis at any stage of its existence. Indeed, while spermatozoa might be capable of surviving for several days post ejaculation, the same cannot be said for the oocyte following ovulation. Once this cell is released from the ovary it has a relatively short period of free existence before it dies an apoptotic death (Perez et al. 2005) or is rescued by the act of fertilization. Prior to their release from the gonads, male germ cells are competent to undergo apoptosis following the activation of meiosis, however, the mechanisms regulating this apoptosis are unclear. There is ample evidence of apoptosis in granulosa cells, leading to the demise of growing oocytes, although whether the oocyte itself can undergo apoptosis while a component of the primordial follicle reserve, once recruited into the growing follicle pool or even following ovulation, is less certain. In the mature testes, differentiating precursor germ cells also undergo apoptosis and again this may be driven directly by the germ line, responding to high levels of DNA damage with the activation of an apoptotic cascade which may be p53 mediated (Odorisio et al. 1998, Kaushai \& Bansal 2009) or indirectly via the disruption of Sertoli cell function. Unlike granulosa cells, the latter do not withdraw support from the germ line by undergoing apoptosis themselves, rather they trigger apoptosis in the germ line by stimulating FAS and FAS ligand expression (Lee et al. 1999).

Clearly, many questions regarding the control of apoptosis in the germ line remain. What is certain is that our ability to manipulate the reproductive life span of mammals is dependent on resolving the precise nature of the apoptotic processes affecting these cells, as well as the physiological triggers that bring about their activation.

\section{Declaration of interest}

The authors declare that there is no conflict of interest that could be perceived as prejudicing the impartiality of the research reported.

\section{Funding}

We gratefully acknowledge the support of the NHMRC program grant (494802), the NH\&MRC Fellowship (\#441101) to J K Findlay, the ARC Centre of Excellence in Biotechnology and Development, and the Victorian and New South Wales State Governments.

\section{References}

Adams JM \& Cory S 2007 The Bcl-2 apoptotic switch in cancer development and therapy. Oncogene 26 1324-1337. (doi:10.1038/sj. onc.1210220)

Aitken RJ \& Curry BJ 2011 Redox regulation of human sperm function: from the physiological control of sperm capacitation to the etiology of infertility and DNA damage in the germ line. Antioxidants \& Redox Signaling 14 367-381. (doi:10.1089/ars.2010.3186)

Aitken RJ \& De luliis GN 2007 Origins and consequences of DNA damage in male germ cells. Reproductive Biomedicine Online 14 727-733. (doi:10.1016/S1472-6483(10)60676-1)

Aitken RJ \& De Iuliis GN 2010 On the possible origins of DNA damage in human spermatozoa. Molecular Human Reproduction 16 3-13. (doi:10.1093/molehr/gap059)

Aitken RJ, West K \& Buckingham D 1994 Leukocytic infiltration into the human ejaculate and its association with semen quality, oxidative stress, and sperm function. Journal of Andrology 15 343-352.

Aitken RJ, Gordon E, Harkiss D, Twigg JP, Milne P, Jennings Z \& Irvine DS 1998 Relative impact of oxidative stress on the functional competence and genomic integrity of human spermatozoa. Biology of Reproduction 59 1037-1046. (doi:10.1095/biolreprod59.5.1037)

Aitken RJ, Koopman P \& Lewis SE 2004 Seeds of concern. Nature 432 48-52. (doi:10.1038/432048a)

Aitken RJ, Wingate JK, De luliis GN, Koppers AJ \& McLaughlin EA 2006 Cisunsaturated fatty acids stimulate reactive oxygen species generation and lipid peroxidation in human spermatozoa. Journal of Clinical Endocrinology and Metabolism 91 4154-4163. (doi:10.1210/jc.2006-1309)

Aitken RJ, De Iuliis GN \& McLachlan RI 2009 Biological and clinical significance of DNA damage in the male germ line. International Journal of Andrology 32 46-56. (doi:10.1111/j.1365-2605.2008.00943.x) 
Aitken RJ, De Iuliis GN, Finnie JM, Hedges A \& McLachlan RI 2010 Analysis of the relationships between oxidative stress, DNA damage and sperm vitality in a patient population: development of diagnostic criteria. Human Reproduction 25 2415-2426. (doi:10.1093/humrep/ deq214)

Albamonte MS, Willis MA, Albamonte MI, Jensen F, Espinosa MB \& Vitullo AD 2008 The developing human ovary: immunohistochemical analysis of germ-cell-specific VASA protein, BCL-2/BAX expression balance and apoptosis. Human Reproduction 23 1895-1901. (doi:10. 1093/humrep/den197)

Almeida C, Sousa M \& Barros A 2009 Phosphatidylserine translocation in human spermatozoa from impaired spermatogenesis. Reproductive Biomedicine Online 19 770-777. (doi:10.1016/j.rbmo.2009.10.002)

Alvarez JG, Touchstone JC, Blasco L \& Storey BT 1987 Spontaneous lipid peroxidation and production of hydrogen peroxide and superoxide in human spermatozoa. Superoxide dismutase as major enzyme protectant against oxygen toxicity. Journal of Andrology 8 338-348.

Baker MA, Reeves G, Hetherington L, Müller J, Baur I \& Aitken RJ 2007 Identification of gene products present in Triton X-100 soluble and insoluble fractions of human spermatozoa lysates using LC-MS/MS analysis. Proteomics. Clinical Applications 1 524-532. (doi:10.1002/ prca.200601013)

Barlow C, Hirotsune S, Paylor R, Liyanage M, Eckhaus M, Collins F, Shiloh Y, Crawley JN, Ried T, Tagle D et al. 1996 Atm-deficient mice: a paradigm of ataxia telangiectasia. Cel/ 86 159-171. (doi:10.1016/S00928674(00)80086-0)

Barlow C, Liyanage M, Moens PB, Tarsounas M, Nagashima K, Brown K, Rottinghaus S, Jackson SP, Tagle D, Ried T et al. 1998 Atm deficiency results in severe meiotic disruption as early as leptonema of prophase I. Development 125 4007-4017.

Barroso G, Morshedi M \& Oehninger S 2000 Analysis of DNA fragmentation, plasma membrane translocation of phosphatidylserine and oxidative stress in human spermatozoa. Human Reproduction $\mathbf{1 5}$ 1338-1344. (doi:10.1093/humrep/15.6.1338)

Bauché F, Fouchard MH \& Jégou B 1994 Antioxidant system in rat testicular cells. FEBS Letters 349 392-396. (doi:10.1016/0014-5793(94)00709-8)

Bennetts LE \& Aitken RJ 2005 A comparative study of oxidative DNA damage in mammalian spermatozoa. Molecular Reproduction and Development 71 77-87. (doi:10.1002/mrd.20285)

Bianchi PG, Manicardi GC, Bizzaro D, Bianchi U \& Sakkas D 1993 Effect of deoxyribonucleic acid protamination on fluorochrome staining and in situ nick-translation of murine and human mature spermatozoa. Biology of Reproduction 49 1083-1088. (doi:10.1095/biolreprod49.5. 1083)

Boaz SM, Dominguez K, Shaman JA \& Ward WS 2008 Mouse spermatozoa contain a nuclease that is activated by pretreatment with EGTA and subsequent calcium incubation. Journal of Cellular Biochemistry 103 1636-1645. (doi:10.1002/jcb.21549)

Borum K 1961 Oogenesis in the mouse. A study of the meiotic prophase. Experimental Cell Research 24 495-507. (doi:10.1016/0014-4827(61) 90449-9)

Byskov AG \& Nielsen M 2003 Ontogeny of the mammalian ovary. In Biology and Pathology of the Oocyte, pp 13-28. Eds AO Trounson \& RG Gosden. Cambridge: Cambridge University Press.

Coucouvanis EC, Sherwood SW, Carswell-Crumpton C, Spack EG \& Jones PP 1993 Evidence that the mechanism of prenatal germ cell death in the mouse is apoptosis. Experimental Cell Research 209 238-247. (doi:10.1006/excr.1993.1307)

Cragg MS, Harris C, Strasser A \& Scott CL 2009 Unleashing the power of inhibitors of oncogenic kinases through $\mathrm{BH} 3$ mimetics. Nature Reviews. Cancer 9 321-326. (doi:10.1038/nrc2615)

De Felici MD, Carlo AD, Pesce M, Iona S, Farrace MG \& Piacentini M 1999 $\mathrm{BCl}-2$ and $\mathrm{Bax}$ regulation of apoptosis in germ cells during prenatal oogenesis in the mouse embryo. Cell Death and Differentiation 6 908-915. (doi:10.1038/sj.cdd.4400561)

De Felici M, Klinger FG, Farini D, Scaldaferri ML, Iona S \& Lobascio M 2005 Establishment of oocyte population in the fetal ovary: primordial germ cell proliferation and oocyte programmed cell death. Reproductive Biomedicine Online 10 182-191. (doi:10.1016/S1472-6483(10)60939-X)

De Felici M, Lobascio AM \& Klinger FG 2008 Cell death in fetal oocytes: many players for multiple pathways. Autophagy 4 240-242.
De luliis GN, Newey RJ, King BV \& Aitken RJ 2009a Mobile phone radiation induces reactive oxygen species production and DNA damage in human spermatozoa in vitro. PLoS ONE 4 e6446. (doi:10.1371/ journal.pone.0006446)

De Iuliis GN, Thomson LK, Mitchell LA, Finnie JM, Koppers AJ, Hedges A, Nixon B \& Aitken RJ 2009b DNA damage in human spermatozoa is highly correlated with the efficiency of chromatin remodeling and the formation of 8-hydroxy-2'-deoxyguanosine, a marker of oxidative stress. Biology of Reproduction 81 517-524. (doi:10.1095/biolreprod.109. 076836)

Den Boer PJ, Poot M, Verkerk A, Jansen R, Mackenbach P \& Grootegoed JA 1990 Glutathione-dependent defence mechanisms in isolated round spermatids from the rat. International Journal of Andrology 13 26-38. (doi:10.1111/j.1365-2605.1990.tb00957.x)

Espino J, Bejarano I, Ortiz A, Lozano GM, García JF, Pariente JA \& Rodríguez AB 2010 Melatonin as a potential tool against oxidative damage and apoptosis in ejaculated human spermatozoa. Fertility and Sterility 94 1915-1917. (doi:10.1016/j.fertnstert.2009.12.082)

Flaws JA, Hirshfield AN, Hewitt JA, Babus JK \& Furth PA 2001 Effect of bcl-2 on the primordial follicle endowment in the mouse ovary. Biology of Reproduction 64 1153-1159. (doi:10.1095/biolreprod64.4.1153)

Flaws JA, Marion SL, Miller KP, Christian PJ, Babus JK \& Hoyer PB 2006 Effect of bcl-2 overexpression in mice on ovotoxicity caused by 4-vinylcyclohexene. Toxicology and Applied Pharmacology 215 51-56. (doi:10.1016/j.taap.2006.03.003)

Frans EM, Sandin S, Reichenberg A, Lichtenstein P, Långström N \& Hultman CM 2008 Advancing paternal age and bipolar disorder. Archives of General Psychiatry 65 1034-1040. (doi:10.1001/archpsyc. 65.9.1034)

Ghafari F, Gutierrez CG \& Hartshorne GM 2007 Apoptosis in mouse fetal and neonatal oocytes during meiotic prophase one. BMC Developmental Biology 7 87. (doi:10.1186/1471-213X-7-87)

Goriely A, Hansen RM, Taylor IB, Olesen IA, Jacobsen GK, McGowan SJ, Pfeifer SP, McVean GA, Meyts ER \& Wilkie AO 2009 Activating mutations in FGFR3 and HRAS reveal a shared genetic origin for congenital disorders and testicular tumors. Nature Genetics 41 1247-1252. (doi:10.1038/ng.470)

Green RF, Devine O, Crider KS, Olney RS, Archer N, Olshan AF \& Shapira SK 2010 Association of paternal age and risk for major congenital anomalies from the National Birth Defects Prevention Study, 1997 to 2004. The National Birth Defects Prevention Study. Annals of Epidemiology 20 241-249. (doi:10.1016/j.annepidem.2009. 10.009)

Greenfeld CR, Pepling ME, Babus JK, Furth PA \& Flaws JA 2007 BAX regulates follicular endowment in mice. Reproduction 133 865-876. (doi:10.1530/REP-06-0270)

Grunewald S, Sharma R, Paasch U, Glander HJ \& Agarwal A 2009 Impact of caspase activation in human spermatozoa. Microscopy Research and Technique 72 868-888. (doi:10.1002/jemt.20732)

Guigon CJ \& Magre S 2006 Contribution of germ cells to the differentiation and maturation of the ovary: insights from models of germ cell depletion. Biology of Reproduction 74 450-458. (doi:10.1095/biolreprod.105. 047134)

Hurst LD \& Ellegren H 2002 Human genetics: mystery of the mutagenic male. Nature 420 365-366. (doi:10.1038/420365a)

Iranpour FG, Nasr-Esfahani MH, Valojerdi MR \& al-Taraihi TM 2000 Chromomycin A3 staining as a useful tool for evaluation of male fertility. Journal of Assisted Reproduction and Genetics 17 60-66. (doi:10.1023/ A:1009406231811)

Irvine DS, Twigg JP, Gordon EL, Fulton N, Milne PA \& Aitken RJ 2000 DNA integrity in human spermatozoa: relationships with semen quality. Journal of Andrology 21 33-44.

Jefferson W, Newbold R, Padilla-Banks E \& Pepling M 2006 Neonatal genistein treatment alters ovarian differentiation in the mouse: inhibition of oocyte nest breakdown and increased oocyte survival. Biology of Reproduction 74 161-168. (doi:10.1095/biolreprod.105.045724)

Joffe M 2010 What has happened to human fertility? Human Reproduction 25 295-307. (doi:10.1093/humrep/dep390)

Kerr JF, Wyllie AH \& Currie AR 1972 Apoptosis: a basic biological phenomenon with wide-ranging implications in tissue kinetics. British Journal of Cancer 26 239-257. 
Kerr JB, Duckett R, Myers M, Britt KL, Mladenovska T \& Findlay JK 2006 Quantification of healthy follicles in the neonatal and adult mouse ovary: evidence for maintenance of primordial follicle supply. Reproduction 132 95-109. (doi:10.1530/rep.1.01128)

Koppers AJ, De luliis GN, Finnie JM, McLaughlin EA \& Aitken RJ 2008 Significance of mitochondrial reactive oxygen species in the generation of oxidative stress in spermatozoa. Journal of Clinical Endocrinology and Metabolism 93 3199-3207. (doi:10.1210/jc.2007-2616)

Koppers AJ, Garg ML \& Aitken RJ 2010 Stimulation of mitochondrial reactive oxygen species production by unesterified, unsaturated fatty acids in defective human spermatozoa. Free Radical Biology \& Medicine 48 112-119. (doi:10.1016/j.freeradbiomed.2009.10.033)

Kurosaka K, Takahashi M, Watanabe N \& Kobayashi Y 2003 Silent cleanup of very early apoptotic cells by macrophages. Journal of Immunology 171 4672-4679.

Lee J, Richburg JH, Shipp EB, Meistrich ML \& Boekelheide K 1999 The Fas system, a regulator of testicular germ cell apoptosis, is differentially up-regulated in Sertoli cell versus germ cell injury of the testis. Endocrinology 140 852-858. (doi:10.1210/en.140.2.852)

Leitch AE, Duffin R, Haslett C \& Rossi AG 2008 Relevance of granulocyte apoptosis to resolution of inflammation at the respiratory mucosa. Mucosal Immunology 1 350-363. (doi:10.1038/mi.2008.31)

Libman J, Gabriel MS, Sairam MR \& Zini A 2010 Catalase can protect spermatozoa of FSH receptor knock-out mice against oxidant-induced DNA damage in vitro. International Journal of Andrology 33 818-822. (doi:10.1111/j.1365-2605.2009.01032.x)

Lin WW, Lamb DJ, Wheeler TM, Abrams J, Lipshultz LI \& Kim ED 1997 Apoptotic frequency is increased in spermatogenic maturation arrest and hypospermatogenic states. Journal of Urology 158 1791-1793. (doi:10. 1016/S0022-5347(01)64130-2)

Ling J \& Söll D 2010 Severe oxidative stress induces protein mistranslation through impairment of an aminoacyl-tRNA synthetase editing site. PNAS 107 4028-4033. (doi:10.1073/pnas.1000315107)

Liu Z, Lin H, Ye S, Liu QY, Meng Z, Zhang CM, Xia Y, Margoliash E, Rao Z \& Liu XJ 2006 Remarkably high activities of testicular cytochrome $\mathrm{C}$ in destroying reactive oxygen species and in triggering apoptosis. PNAS 103 8965-8970. (doi:10.1073/pnas.0603327103)

Lobascio AM, Klinger FG \& De Felici M 2007a Isolation of apoptotic mouse fetal oocytes by AnnexinV assay. International Journal of Developmental Biology 51 157-160. (doi:10.1387/ijdb.062203al)

Lobascio AM, Klinger FG, Scaldaferri ML, Farini D \& De Felici M 2007 b Analysis of programmed cell death in mouse fetal oocytes. Reproduction 134 241-252. (doi:10.1530/REP-07-0141)

Lolis D, Georgiou I, Syrrou M, Zikopoulos K, Konstantelli M \& Messinis I 1996 Chromomycin A3-staining as an indicator of protamine deficiency and fertilization. International Journal of Andrology 19 23-27. (doi:10. 1111/j.1365-2605.1996.tb00429.x)

Lozano GM, Bejarano I, Espino J, González D, Ortiz A, García JF, Rodríguez AB \& Pariente JA 2009 Relationship between caspase activity and apoptotic markers in human sperm in response to hydrogen peroxide and progesterone. Journal of Reproduction and Development $\mathbf{5 5}$ 615-621. (doi:10.1262/jrd.20250)

McLaren A 1988 The developmental history of female germ cells in mammals. Oxford Reviews of Reproductive Biology 10 162-179.

McLaren A 2000 Germ and somatic cell lineages in the developing gonad. Molecular and Cellular Endocrinology 163 3-9. (doi:10.1016/S03037207(99)00234-8)

Meyer-Ficca ML, Lonchar J, Credidio C, Ihara M, Li Y, Wang ZQ \& Meyer RG 2009 Disruption of poly(ADP-ribose) homeostasis affects spermiogenesis and sperm chromatin integrity in mice. Biology of Reproduction 81 46-55. (doi:10.1095/biolreprod.108.075390)

Michalak EM, Jansen ES, Happo L, Cragg MS, Tai L, Smyth GK, Strasser A, Adams JM \& Scott CL 2009 Puma and to a lesser extent Noxa are suppressors of Myc-induced lymphomagenesis. Cell Death and Differentiation 16 684-696. (doi:10.1038/cdd.2008.195)

Motta PM, Nottola SA \& Makabe S 1997 Natural history of the female germ cell from its origin to full maturation through prenatal ovarian development. European Journal of Obstetrics, Gynecology, and Reproductive Biology 75 5-10. (doi:10.1016/S0301-2115(97)00216-9)

Murdoch WJ, Van Kirk EA, Vonnahme KA \& Ford SP 2003 Ovarian responses to undernutrition in pregnant ewes, USA. Reproductive Biology and Endocrinology 1 6. (doi:10.1186/1477-7827-1-6)
Odorisio T, Rodriguez TA, Evans EP, Clarke AR \& Burgoyne PS 1998 The meiotic checkpoint monitoring synapsis eliminates spermatocytes via p53-independent apoptosis. Nature Genetics 18 257-261. (doi:10. 1038/ng0398-257)

Paasch U, Grunewald S, Agarwal A \& Glandera HJ 2004 Activation pattern of caspases in human spermatozoa. Fertility and Sterility $\mathbf{8 1}$ (Supplement 1) 802-809. (doi:10.1016/j.fertnstert.2003.09.030)

Pepling ME 2006 From primordial germ cell to primordial follicle: mammalian female germ cell development. Genesis 44 622-632. (doi:10.1002/dvg.20258)

Pepling ME \& Spradling AC 2001 Mouse ovarian germ cell cysts undergo programmed breakdown to form primordial follicles. Developmental Biology 234 339-351. (doi:10.1006/dbio.2001.0269)

Perez GI, Jurisicova A, Matikainen T, Moriyama T, Kim MR, Takai Y, Pru JK, Kolesnick RN \& Tilly JL 2005 A central role for ceramide in the agerelated acceleration of apoptosis in the female germline. FASEB Journal 19 860-862. (doi:10.1096/fj.04-2903fje)

Perez GI, Jurisicova A, Wise L, Lipina T, Kanisek M, Bechard A, Takai Y, Hunt P, Roder J, Grynpas M et al. 2007 Absence of the proapoptotic Bax protein extends fertility and alleviates age-related health complications in female mice. PNAS 104 5229-5234. (doi:10.1073/pnas. 0608557104)

Pesce M \& De Felici M 1994 Apoptosis in mouse primordial germ cells: a study by transmission and scanning electron microscope. Anatomy and Embryology 189 435-440. (doi:10.1007/BF00185438)

Piña-Guzmán B, Solís-Heredia MJ, Rojas-García AE, Urióstegui-Acosta M \& Quintanilla-Vega B 2006 Genetic damage caused by methyl-parathion in mouse spermatozoa is related to oxidative stress. Toxicology and Applied Pharmacology 216 216-224. (doi:10.1016/j.taap.2006.05.001)

Pittman DL, Cobb J, Schimenti KJ, Wilson LA, Cooper DM, Brignull E, Handel MA \& Schimenti JC 1998 Meiotic prophase arrest with failure of chromosome synapsis in mice deficient for Dmc1, a germline-specific RecA homolog. Molecular Cell 1 697-705. (doi:10.1016/S10972765(00)80069-6)

Pujianto DA, Curry BJ \& Aitken RJ 2010 Prolactin exerts a prosurvival effect on human spermatozoa via mechanisms that involve the stimulation of Akt phosphorylation and suppression of caspase activation and capacitation. Endocrinology 151 1269-1279. (doi:10.1210/en.2009-0964)

Ratts VS, Flaws JA, Kolp R, Sorenson CM \& Tilly JL 1995 Ablation of bcl-2 gene expression decreases the numbers of oocytes and primordial follicles established in the post-natal female mouse gonad. Endocrinology 136 3665-3668. (doi:10.1210/en.136.8.3665)

Reichenberg A, Gross R, Weiser M, Bresnahan M, Silverman J, Harlap S, Rabinowitz J, Shulman C, Malaspina D, Lubin G et al. 2006 Advancing paternal age and autism. Archives of General Psychiatry 63 1026-1032. (doi:10.1001/archpsyc.63.9.1026)

Rodrigues P, Limback D, McGinnis LK, Plancha CE \& Albertini DF 2009 Multiple mechanisms of germ cell loss in the perinatal mouse ovary. Reproduction 137 709-720. (doi:10.1530/REP-08-0203)

Rodriguez I, Ody C, Araki K, Garcia I \& Vassalli P 1997 An early and massive wave of germinal cell apoptosis is required for the development of functional spermatogenesis. EMBO Journal 16 2262-2270. (doi:10. 1093/emboj/16.9.2262)

Rossi A \& Aitken RJ 1997 Interactions between leukocytes and the male reproductive system, the unanswered questions. Advances in Experimental Medicine and Biology 424 245-252.

Rucker EB III, Dierisseau P, Wagner KU, Garrett L, Wynshaw-Boris A, Flaws JA \& Hennighausen $\mathbf{L} 2000 \mathrm{BCl}-\mathrm{x}$ and Bax regulate mouse primordial germ cell survival and apoptosis during embryogenesis. Molecular Endocrinology 14 1038-1052. (doi:10.1210/me.14.7.1038)

Shimura T, Inoue M, Taga M, Shiraishi K, Uematsu N, Takei N, Yuan ZM, Shinohara T \& Niwa O 2002 p53-dependent S-phase damage checkpoint and pronuclear cross talk in mouse zygotes with X-irradiated sperm. Molecular and Cellular Biology 22 2220-2228. (doi:10.1128/MCB.22.7.2220-2228.2002)

Shuster LT, Rhodes DJ, Gostout BS, Grossardt BR \& Rocca WA 2010 Premature menopause or early menopause: long-term health consequences. Maturitas 65 161-166. (doi:10.1016/j.maturitas.2009.08.003)

Singh NP, Muller CH \& Berger RE 2003 Effects of age on DNA doublestrand breaks and apoptosis in human sperm. Fertility and Sterility $\mathbf{8 0}$ 1420-1430. (doi:10.1016/j.fertnstert.2003.04.002) 
Sipos A, Rasmussen F, Harrison G, Tynelius P, Lewis G, Leon DA \& Gunnell D 2004 Paternal age and schizophrenia: a population based cohort study. BMJ 329 1070. (doi:10.1136/bmj.38243.672396.55)

Sotolongo B, Huang TT, Isenberger E \& Ward WS 2005 An endogenous nuclease in hamster, mouse, and human spermatozoa cleaves DNA into loop-sized fragments. Journal of Andrology 26 272-280.

Tam PP \& Snow MH 1981 Proliferation and migration of primordial germ cells during compensatory growth in mouse embryos. Journal of Embryology and Experimental Morphology 64 133-147.

Tilly JL 2001 Commuting the death sentence: how oocytes strive to survive. Nature Reviews. Molecular Cell Biology 2 838-848. (doi:10.1038/ 35099086)

Tingen CM, Bristol-Gould SK, Kiesewetter SE, Wellington JT, Shea L \& Woodruff TK 2009 Prepubertal primordial follicle loss in mice is not due to classical apoptotic pathways. Biology of Reproduction 81 16-25. (doi:10.1095/biolreprod.108.074898)

Tremellen K \& Tunc O 2010 Macrophage activity in semen is significantly correlated with sperm quality in infertile men. International Journal of Andrology 33 823-831. (doi:10.1111/j.1365-2605.2009.01037.x)

Twigg JP, Irvine DS \& Aitken RJ 1998 Oxidative damage to DNA in human spermatozoa does not preclude pronucleus formation at intracytoplasmic sperm injection. Human Reproduction 13 864-871.

Vaskivuo TE, Anttonen M, Herva R, Billig H, Dorland M, Velde ER, Stenback F, Heikinheimo M \& Tapanainen JS 2001 Survival of human ovarian follicles from fetal to adult life:apoptosis, proteins, and transcription factor GATA-4. Journal of Clinical Endocrinology and Metabolism 86 3421-3429. (doi:10.1210/jc.86.7.3421)
Wang C, Cui YG, Wang XH, Jia Y, Sinha Hikim A, Lue YH, Tong JS, Qian LX, Sha JH, Zhou ZM et al. 2007 Transient scrotal hyperthermia and levonorgestrel enhance testosterone-induced spermatogenesis suppression in men through increased germ cell apoptosis. Journal of Clinical Endocrinology and Metabolism 92 3292-3304. (doi:10.1210/jc. 2006-2019)

Yoshida K, Kondoh G, Matsuda Y, Habu T, Nishimune Y \& Morita T 1998 The mouse RecA-like gene Dmc1 is required for homologous chromosome synapsis during meiosis. Molecular Cell 1 707-718. (doi:10.1016/S1097-2765(00)80070-2)

Youle RJ \& Strasser A 2008 The BCL-2 protein family: opposing activities that mediate cell death. Nature Reviews. Molecular Cell Biology 9 47-59. (doi:10.1038/nrm2308)

Zhu JL, Vestergaard M, Madsen KM \& Olsen J 2008 Paternal age and mortality in children. European Journal of Epidemiology 23 443-447. (doi:10.1007/s10654-008-9253-3)

Zini A, Boman JM, Belzile E \& Ciampi A 2008 Sperm DNA damage is associated with an increased risk of pregnancy loss after IVF and ICSI: systematic review and meta-analysis. Human Reproduction 23 2663-2668. (doi:10.1093/humrep/den321)

Received 20 May 2010

First decision 13 July 2010

Revised manuscript received 24 November 2010

Accepted 9 December 2010 